\title{
Educação básica, Biblioteca e Espírito científico: circunstâncias e oportunidades
}

\author{
Basic education, Library and Scientific Spirit: circumstances and opportunities
}

\author{
Eliane Fioravante Garcez \\ Mestre em Ciência da Informação pela Universidade Federal de Santa Catarina - UFSC \\ E-mail: efgarcez@ig.com.br
}

\begin{abstract}
Resumo
Discorre sobre a escola e os reflexos das mudanças sociais nela e a partir dela. Aborda a questão da re-produção do conhecimento e sua repercussão no social. Sucintamente, apresenta dados sobre a avaliação do ensino brasileiro através do Censo Escolar de 2010 e do Relatório Pisa/OECD de 2009, estreitando a relação entre a Política Nacional de Educação e as perspectivas de desenvolvimento do país. Trata sobre a questão da pesquisa científica, a partir do seu nascedouro, a escola de Educação Básica. A prática de trabalhos-cópia tem revelado sério problema nesse ensino, que repercute nos demais níveis educacionais. Vislumbra a possibilidade de uma reorganização curricular onde o aluno tenha oportunidade de exercitar-se autor. Essa premissa atende as perspectivas da construção do conhecimento, do desenvolvimento da autonomia, e de se avançar em ciência e em tecnologia. Garantir recursos, pessoas qualificadas e um currículo que ilumine o caminho transcorrido pelo aluno durante as etapas da pesquisa escolar são entendidos como prioritários na construção do espírito científico a partir da Educação Básica. Aborda a necessidade da ampliação de número de escolas com bibliotecas e laboratórios de ciências (química, física, biologia e matemática), e de profissionais qualificados para melhor orientar os alunos no uso desses recursos na escola.
\end{abstract}

Palavras-Chave: Educação Básica. Desenvolvimento científico. Pesquisa Escolar. Biblioteca. Currículo.

\begin{abstract}
The study is about the school and the repercussions of the of the social changes from and in it. It's about the issue of re-production of knowledge and its impact on society. Presents data from the evaluation of Brazilian education through the School Census of 2010 and of Report Pisa/OECD, 2009, which show the close relationship between the National Policy on Education and the development prospects of the country. Treat of the question of scientific research from its outset: the School of Basic Education. The practice of "work-copy" has revealed serious problem in this teaching and has influence at the other levels of education. It sees the possibility of reorganizing curriculum where the student has the opportunity to work like an author. This premise serves the prospects of building knowledge, development of autonomy, and to advance in science and technology. Thus, the security of resources, qualified personnel and a curriculum that illuminate the path passed by the student through the steps of the research school, is a priority for the construction of the scientific spirit from the Basic Education. Deal with the need to expand the number of schools with libraries and science laboratories (chemistry, physics, biology and mathematics), and qualified professionals to better guide students in using these resources at school.
\end{abstract}

Keywords: Primary Education. Scientific development. School Research. Library. Curriculum. 


\section{Introdução}

A concepção do ensino no Brasil empurrou o espírito de pesquisa para a pósgraduação, tornando impossível, ou pelo menos muito difícil, estimular a criatividade, imprescindível a qualquer investigação. Investigar exige invenção, e isso deve existir desde o pré-primário ${ }^{1}$, e não apenas para pósgraduandos. (MILANESI, 1983, p. 65.)

Os desafios do ensino e da aprendizagem na atual sociedade estão intrínsecos à necessidade de preparar as futuras gerações num mundo fortemente operado por novas tecnologias. Afinal, como as crianças e os jovens estão aprendendo nesse ambiente social em acelerada metamorfose? Como os profissionais vêm sendo preparados para atender tal demanda? E, considerando a pouca disponibilidade de recursos de acesso à informação e a enorme necessidade de se ensinar os alunos a operá-la desde a Educação Básica, como o currículo conseguirá corresponder à dinâmica dos novos tempos?

Para Charlot (2005), na atual sociedade a escola precisa ser para o aluno ambiente gerador de sentido. Isso é fundamental para que o interesse dele pela escola e pelo saber seja instigado e alimentado. Quanto mais sentido tiver o que está sendo ensinado, mais o aluno se mobiliza para se relacionar com o conteúdo. Este ideal não é predominante na escola. Defende esse autor que:

o direito à educação não é simplesmente o direito de ir à escola; mas o direito à apropriação efetivas dos saberes, dos saberes que fazem sentidos -e não de simples informações dadas pelo professor ou encontradas na internet -, de saberes que esclareçam o mundo. (CHARLOT, 2005, p. 148).

Outro francês que compartilha da ideia de que a escola precisa instigar o desejo pelo saber é Lobrot (1992). Para isso, no entender desse autor, a escola deve ser:

viva e centrada nas pessoas em formação [...] obedecer a um duplo movimento: no sentido da informação pura e no sentido da animação. Poderíamos conceber de um lado uma estrutura centrada inteiramente sobre $o$ saber $e$ os conhecimentos, que seria composta de bibliotecas, de especialistas a que se poderia recorrer, de meios materiais de estudo, de instrumentos audiovisuais, de máquinas programadas, etc., e do outro uma estrutura para ajudar os alunos a comunicar entre eles, a viver experiências desejadas, a afirmar os seus objectivos, a elaborar os seus fins, a pôr os seus problemas, que seria gerada e enquadrada por animadores competentes. [...] com a possibilidade de encontrarem um alimento ao desejo de saber. (LOBROT, 1992, p.119, grifo meu).

\footnotetext{
${ }^{1}$ Refere-se à educação pré-escolar. A nomenclatura "ensino primário", eliminada da educação brasileira através da Lei 5.692/71 quando implantou o ensino de primeiro grau - atualmente denominado de Ensino Fundamental. (SAVIANI et al. O legado educacional do século XX no Brasil. 2005).
} 
Percebe-se, a partir dos autores com quem "converso" neste texto, uma emergência em instrumentalizar a escola e demais espaços sociais com recursos, e em apostar numa nova forma de envolver os indivíduos com o conhecimento produzido, proporcionando-lhes mais e melhores condições para gestarem conhecimento novo. Para alcançar tais objetivos, será necessário investir em estrutura física, evidentemente, mas rever o currículo (prescrição e ação), qualificando alunos e professores - futuros animadores competentes, como denominado por Lobrot (1992). Aplicada de forma contínua, tal medida fará com que o processo de ensino - da base à ponta - ou seja, do ensino fundamental à pós-graduação, não se rompa, garantindo a operacionalização de uma aprendizagem amparada na leitura e na reflexão, fundamentos do ideal de pesquisa escolar - a semente do espírito investigativo - que precisa ser plantada.

O presente artigo aborda questões que perpassam pelo investimento em pesquisa condição imprescindível ao desenvolvimento do espírito científico - o qual tem direta relação com o quê e o como se ensina e se aprende na Educação Básica.

\section{O Desenvolvimento do Espiríto Científico e a Escola}

O déficit educacional brasileiro tem comprometido a participação social de parte expressiva da população, determinando o grau de desenvolvimento e o avanço científico desse país. Segundo o Censo Escolar 2010² (BRASIL, 2010b), temos 51,5 milhões de estudantes matriculados na Educação Básica. Quanto aos dados relacionados à infraestrutura escolar (Biblioteca, Laboratório de Ciências e de Informática e acesso à Internet) - subsídio para a prática da reflexão na escola - depara-se com o seguinte quadro.

\begin{tabular}{|l|c|c|c|}
\hline \multirow{2}{*}{ Infraestrutura Escolas } & \multicolumn{2}{|c|}{ Ensino Fundamental } & \multirow{2}{*}{ Ensino Médio } \\
\cline { 2 - 3 } & $1^{\mathbf{o}}$ ao $5^{\mathbf{o}}$ ano & $6^{\mathbf{o}}$ ao $9^{\mathbf{o}}$ ano & \\
\hline Biblioteca & $30,4 \%$ & $58,7 \%$ & $74 \%$ \\
\hline Laboratório de Ciências & $7,6 \%$ & $23,8 \%$ & $49,3 \%$ \\
\hline Laboratório de Informática & $32,3 \%$ & $67,6 \%$ & $89,3 \%$ \\
\hline
\end{tabular}

\footnotetext{
${ }^{2}$ Neste artigo serão apresentados dados referentes ao Censo Escolar 2010. Os do Censo Escolar 2011, ainda não foram divulgados integralmente. A segunda etapa de coleta de dados que aconteceu entre 1 fevereiro. a 13 março de 2012, busca conhecer o rendimento escolar dos alunos no ano de 2011 - se aprovado, reprovado ou deixou de frequentar a escola. Sobre o Censo Escolar 2011, no site do Instituto Nacional de Estudos e Pesquisas Educacionais Anísio Teixeira (Inep), há apenas dois anexos referentes ao quantitativo de matrículas nas instituições estaduais e municipais, nas áreas urbana e rural (Brasil, Estados e respectivos municípios), e que podem vir a ser alterados com base nos dados levantados na segunda etapa da coleta. Disponível em: <http://portal.inep.gov.br/basica-censo>. Acesso em: 15 mar. 2012.
} 


\begin{tabular}{|l|l|l|l|}
\hline acesso à Internet & $38,9 \%$ & $70 \%$ & $94,3 \%$ \\
\hline
\end{tabular}

Quadro Único: Infraestrutura informacional na Educação Básica

Fonte: Adaptação de Brasil (2010b, p. 33- 35).

A partir desses dados, nota-se que à medida que os alunos avançam nos anos escolares, a cobertura de escolas com bibliotecas aumenta. No entanto, nos dois níveis de ensino (Fundamental e Médio), dos quatro itens arrolados, o acesso à Internet é o que apresenta maior percentual de cobertura, alcançando 94,3\% das escolas brasileiras de Ensino Médio, mas não de alunos. A oferta de Laboratório de Informática, que também aumenta no Ensino Médio, é maior do que a de Biblioteca.

No entanto, mesmo que o percentual de escolas de Educação Básica com bibliotecas, ainda, seja pequeno, acima apenas do número de escolas com Laboratório de Ciências, o que a maioria da população estudantil brasileira, conta mesmo, segundo Moro e Estabel (2004, p. 5), é com o livro para realizar as suas pesquisas e trabalhos escolares ${ }^{3}$.

O material disponível para a realização da pesquisa escolar, tem como suporte, na grande maioria, o livro, pois a internet, quando existe na escola pública, tem prioridade nos laboratórios de informática ou na secretaria, preterindo a biblioteca e o atendimento aos seus usuários.

A ausência de bibliotecas nas escolas de Educação Básica - $69 \%$ nas de $1^{\circ}$ ao $6^{\circ}$ ano e 41,3\% nas de $6^{\circ}$ ao $9^{\circ}$ ano do Ensino Fundamental, e 26\% nas de Ensino Médio - (BRASIL, 2010b), faz supor que o livro a que a maioria dos alunos utiliza nas atividades escolares é aquele distribuído pelo Programa Nacional do Livro Didático (PNLD), pelo Programa Nacional do Livro Didático Ensino Médio (PNLEM), e pelo Programa Nacional Biblioteca da Escola (PNBE). Mas, em quais condições se encontram livros (conservação, atualização, variedade e quantidade disponível) e alunos e como esses últimos vêm realizando suas atividades? Hoje, com o conhecimento sendo veiculado em diferentes suportes, a predominância do uso do livro didático no meio escolar indica que é preciso instituir e dinamizar bibliotecas escolares. Além disso, é necessário orientar e estimular os alunos para que saibam utilizar os recursos disponíveis nela. Leitura é base para a pesquisa. Neste sentido, a pesquisa escolar e a pesquisa científica devem refletir a percepção e a compreensão do que foi lido e experimentado pelo aluno/pesquisador. Por certo, isso sendo compreendido, ficará

\footnotetext{
${ }^{3}$ Expressão bastante usual no âmbito escolar. Aquilo que não é, mas que acreditamos possa vir a ser pesquisa escolar, se forem oferecidos recursos, orientação e tempo para que o aluno possa ler e manifestar o que leu através da escrita, amparada na metodologia científica (principalmente no que concerne à citação, indicação de fontes, introdução e conclusão), adaptada ao nível de ensino e a série do aluno.
} 
mais claro aos gestores públicos e à comunidade escolar, reconhecer a importância de se investir na biblioteca.

Ainda, o Censo Escolar (BRASIL, 2010b, p. 40-42) registra que algumas escolas oferecem cursos de atividades complementares, como "uso e acesso à Software educacional/Linux; Informática e Tecnologia da informação", mas, quando se pensará em oferecer aos alunos curso de Atividade Complementar de orientação à pesquisa escolar? Será que as escolas de Educação Básica têm pensado nessa necessidade e possibilidade? O fato é que o avanço do país, a sua dependência técnica-econômico-financeira e a inclusão social do seu povo estão relacionadas aos dados do quadro único deste artigo.

A infraestrutura informacional - Biblioteca, Laboratório de Ciências e de Informática e acesso à Internet - oferecida à Educação Básica deve ser assegurada à totalidade de alunos das unidades escolares brasileiras, assim como a necessidade de se pensar numa nova sistemática curricular que faça com que alunos e professores utilizem tais recursos de forma intensa, ativa e competente. Esse aspecto está relacionado ao resultado dos estudos apontados no Relatório Pisa 2009, da Organisation for Economic Cooperation and Development (OECD) (OECD, 2010).

Trienalmente, a partir de 2000, a OECD, através do Programme for International Student Assessment (PISA), vem avaliando, nos cinco continentes, os conhecimentos e as habilidades em jovens na faixa etária de 15 anos. O propósito é conhecer, avaliar e projetar as condições que esses jovens terão ao final da educação obrigatória, fazendo uma prospecção de como estarão participando/contribuindo na/para a sociedade do conhecimento. Além disso, nesses estudos estão alicerçadas as perspectivas que os bancos mundiais terão como garantia de retorno aos investimentos aplicados nesses países. A mais recente avaliação (OECD, 2010), centrada na leitura, denunciou que a educação brasileira a ser assegurada pelo Governo e pelo empresariado - vez que os alunos avaliados pertencem tanto ao ensino público quanto ao privado, precisa ser melhorada. Dos 65 países inscritos, o Brasil ficou na $53^{\text {a }}$ colocação, seguido por Chile $\left(44^{\circ}\right)$, Uruguai $\left(47^{\circ}\right)$, Trinidad e Tobago $\left(51^{\circ}\right)$ e Colômbia $\left(52^{\circ}\right)$. (OECD, 2010). Os índices revelam que o Governo brasileiro precisa investir numa educação de qualidade. Lembra Zouain (2001, p. 67), que "uma grande contribuição dos governos à acumulação tecnológica faz-se de seu investimento em educação e treinamento." Para essa autora, essas áreas estão relacionadas à situação socioeconômica e de desenvolvimento de um país. Elas são tão marcantes que refletem nas concepções e na conduta dos indivíduos, dos 
Governos e das instituições de pesquisa, dividindo o mundo em dois blocos ou em duas civilizações; uma que pensa e outra que executa. Segundo Salomon et al apud Zouain (2001, p. 19), essas civilizações "mantêm uma interação em único sentido: "a segunda civilização é dependente e profundamente afetada pela primeira faltando-lhe a capacidade de influenciá-la na mesma medida."

A escola é o sustentáculo da desejada capacitação tecnológica, capacitação esta que depende, principalmente, de ações do governo e da classe empresarial. A política educacional de um país está fortemente relacionada ao desenvolvimento em ciência e em tecnologia e estas aos aspectos culturais e educacionais. (ZOUAIN, 2001). Deste modo, cabe ao Estado criar e viabilizar ações para que a escola contribua para minimizar a dependência tecnológica e econômica que o país, ainda, se encontra. Falta ao Brasil uma política nacional, e de longo prazo, que estimule o surgimento e o desenvolvimento de novos cientistas, que promova aprendizado em todas as áreas e que incentive a descoberta de novos mundos. (MACIEL, 2005). Mas como descobrir novos mundos sem viabilizar e expandir o acesso à informação? Como uma educação centrada nos livros didáticos e no professor, carecendo de biblioteca, de laboratórios e de outras condições de ordem estrutural e conjuntural poderá estimular os alunos para que aprendam e façam uso da informação, se interessem por outros mundos, a partir do contexto local do qual se encontram?

Pensando sobre a vinculação e a veiculação de informações e de conhecimento que acontecem entre o local e o global, ou entre diferentes mundos, Bianchetti (2008, p. 57) alerta de que é preciso garantir condições para que as trocas ocorram de forma igualitária, o que "pressupõem-se meios e pessoas qualificadas". Para Maciel (2005, p. 110, grifo meu) isso exigirá "formação de novos profissionais para a produção e transmissão da ciência; maior (e melhor) presença da ciência nos meios de comunicação impressos e audiovisuais; e mudanças indispensáveis e urgentes no ensino fundamental." Percebe-se, nestas considerações, a vinculação entre a formação profissional e as mudanças na Educação Básica, porque delas dependerá a formação de novos professores, de novos pesquisadores e de futuros cidadãos. De acordo com Maciel (2005, p. 109), a escola precisa viabilizar o "aprender, portanto, a responder ao interesse e à curiosidade natural tanto da criança quanto do público adulto, visando a uma divulgação mais ampla do conhecimento científico e do seu entendimento." Vogt (2001) enfatiza que além da reforma curricular, do reforço didático-pedagógico e dos recursos para operacionalizá-los, é preciso pensar em treinamento e capacitação aos professores que já estão na escola. Esse autor mostra-se temeroso com a falta de 
investimentos na educação, pois com essa carência, o Brasil irá usufruir pouco, dos muitos benefícios oferecidos pelas TIC.

A pesquisa sobre o uso das Tecnologias da Informação e da Comunicação no Brasil “TIC Domicílios 2009”, mostrou que 36\% das residências possuíam computador e dessas $27 \%$ utilizavam a internet. Entre 2008 e 2009 o percentual de notebooks nos lares brasileiros cresceu cerca de 70\%. (VERONESE, 2010). Naquele momento Balboni apud Veronese (2010, p. 18, grifo meu), dizia que “o cenário é otimista, já que, além da grande expansão no acesso, vemos um uso mais qualificado da rede, com usuários mais hábeis e familiarizados com o computador e com a rede." Contudo, treinamento para navegar na Web difere da orientação que os navegadores precisam para terem uso qualificado da informação disponível nesse meio. E aqui cabe novamente a pergunta: como esses usuários domiciliares vêm utilizando esse recurso e até que ponto isso nos remete à forma como se dá a inserção da internet na escola? Os alunos lêem, refletem e constroem novas ideias a partir das informações que encontram nela, ou simplesmente as copiam?

Os dados mais recentes sobre o uso das TIC, coletados em setembro/novembro de 2010, - "TIC Domicílios e Usuários 2010" - revelou que 31\% das residências pesquisadas, localizadas em área urbana, possui acesso à internet via computador de mesa ou laptop e notebook. Dos entrevistados (contabilizados estudantes, aposentados e donas de casa) 87\% utilizam a internet para buscar informações e serviços on-line. Das nove opções de resposta sobre o que procuram na rede, "Buscar informações em sites de enciclopédia virtual" ocupou a quarta posição, e "Buscar informações em dicionários gratuitos", a sexta. A proporção desses indivíduos que usaram a internet, especificamente, para fins de educação é de $66 \%$. Dos jovens entre 10 a 15 anos (faixa etária que normalmente está cursando as séries finais do Ensino fundamental e Ensino Médio), 90\% utiliza a internet para este fim. Das respostas às atividades desenvolvidas na internet para treinamento e educação, em primeiro lugar encontra-se "Realizar atividades/pesquisas escolares", seguida de "Informar-se sobre a disponibilidade de um livro ou artigo na biblioteca", "Buscar informações sobre cursos de graduação, pós-graduação e extensão", "Baixar/fazer o download de material" e "Fazer cursos on-line". No entanto $\mathbf{3 4 \%}$ informou não ter utilizado a internet para fins de educação nos três últimos meses anteriores à coleta de dados, sendo que a maior concentração desses respondentes encontra-se na região Sul. A faixa etária de 10 a 15 anos lidera com $88 \%$ o acesso à internet para "Realizar atividades/pesquisas escolares". Acerca das dificuldades no uso da internet, das dez opções de resposta apresentadas aos 
entrevistados, as três mais indicadas, numa ordem decrescente, foram: "Não encontrar a informação desejada no site", "Ler um texto longo na Internet", e "Localizar um site específico pelas ferramentas de busca, como o Google". Essa mesma sequencia de dificuldades para uso da internet foi indicada por aqueles que estão no Ensino Fundamental e Médio. Dos entrevistados que nunca utilizaram a internet, mas, apenas, o computador, as razões mais indicadas para isso foram: "Falta de habilidade com o computador/Internet", "Não tem necessidade/interesse", "Não tem de onde acessar", "Não tem condições de pagar $o$ acesso" e "Outros". (CENTRO DE ESTUDOS SOBRE AS TECNOLOGIAS DA INFORMAÇÃO E DA COMUNICAÇÃO, 2010a).

A “TIC Educação 2010 - alunos", realizada em setembro/dezembro de 2010, revelou que, $44 \%$ dos alunos participantes da pesquisa têm acesso à internet em casa. Destes 54\% estão no Ensino Médio, $46 \%$ na $8^{\mathrm{a}}$ série, ou $9^{\circ}$ ano, e $35 \%$ na $4^{\mathrm{a}}$ série, ou $5^{\circ}$ ano, do Ensino Fundamental. Quanto à maneira que os alunos entrevistados encontram para obter as habilidades para uso do computador, em quarto lugar encontra-se a opção "Em uma instituição formal de ensino (escola, etc)." Das atividades escolares com o uso do computador e internet, os itens mais votados foram: para "Fazer projetos ou trabalhos sobre um tema (como aquecimento global, Copa do Mundo, Dia das Mães, etc.)", "Fazer pesquisa para a escola em enciclopédias, revistas e notícias", "Aprender a usar o computador e a Internet", "Escrever textos, fazer desenhos, maquetes, etc.," "Fazer lição/exercícios que o professor passa" e "Jogar jogos educativos". Quanto ao local de uso do computador e da internet para realizar estas atividades, de onze opções oferecidas para resposta, a mais indicada foi o "computador de casa", seguido de "em outro local" e "na escola". Quando as atividades com uso do computador e da internet são feitas na escola os dois locais mais utilizados são o Laboratório de Informática (93\%) e a Biblioteca (5\%). Com relação à frequência de uso do computador e internet, a maioria respondeu que ela ocorre "de vem em quando".

Dos alunos que já tinham utilizado computador ou internet alguma vez, as três formas de aprendizado para lidar com ele/ela mais indicadas foram: com "filhos, parentes, amigos, etc", "Sozinho", "Fez um curso específico", seguidos por "Com outro professor ou educador da escola", e "Com os alunos/com um aluno". (CENTRO DE ESTUDOS SOBRE AS TECNOLOGIAS DA INFORMAÇÃO E DA COMUNICAÇÃO, 2010b). 
Apesar de as escolas brasileiras terem mais internet do que biblioteca, (BRASIL, 2010b), no computo geral, a grande parte dos escolares não tem nem biblioteca e nem internet na escola. Em casa a maioria dos escolares também não tem acesso à rede. Então, como estimular os alunos para à leitura, à pesquisa e incutir neles o espírito investigativo? A partir das respostas dos que vêm utilizando o computador e a internet, ficou evidente a necessidade de a escola orientá-los para que consigam desenvolver habilidades de uso da informação, estando ela na internet ou na biblioteca.

Wagner (2010) e Blattmann e Fragoso (2003) lembram que:

inclusão digital não significa apenas ter acesso a um computador e à Internet. É preciso saber utilizar esses recursos para atividades variadas, em três diferentes patamares [...] [ : ] comunicação entre as pessoas, [...] obtenção de informações e a utilização de serviços de interesse público [...] geração e a disponibilização de conteúdo, através das mais diferentes formas - geração de conteúdos multimídia, digitalização de conteúdos variados, criação de páginas e de blogs etc. (WAGNER, 2010, n. p., grifo meu).

É preciso tomar cuidados ao introduzir tecnologias em escolas, empresas e na vida pessoal. Não bastam computadores conectados à internet $\mathrm{e}$ completos recursos de multimídia. Necessita-se oferecer orientação, acompanhamento, instrução, treinamento gradativo aos diretamente envolvidos. (BLATTMANN; FRAGOSO, 2003, p. 65, grifo meu).

Wagner (2010), assim como Vogt (2001), enfatiza a necessidade da capacitação dos professores. Para esse autor o investimento não deve ser apenas no acesso a essa tecnologia, mas na educação e no desenvolvimento mais global do cidadão.

A ligação das escolas em banda larga não será suficiente, se os professores
ou outros instrutores que atuam nas escolas não forem capazes de transmitir
aos alunos as habilidades básicas no uso dos computadores e da Internet. [...]
Logo, a Informática precisa entrar definitivamente na vida escolar,
especialmente nas escolas públicas, o que será possível quando os
professores forem capazes de utilizar de forma mais avançada os
computadores e a Internet no ensino de suas próprias matérias, como
Biologia, História ou Português. Para que isso ocorra, é necessário o
treinamento e a disponibilização, através da Internet ou do próprio
computador da escola, de ferramentas e de conteúdos didáticos de boa
qualidade, em língua portuguesa [...]. (WAGNER, 2010, n.p, grifo meu).

É oportuno salientar que habilidade é algo que não se transmite, mas se desenvolve. Portanto, é preciso oferecer às pessoas, desde a escola, instrumentos, orientação e oportunidade de convívio com a informação, independentemente do suporte onde esteja registrada, seja no meio impresso, virtual ou eletrônico. Diante disso, surge o questionamento: será que as TIC concorrem para que a biblioteca escolar, ainda bastante distante das práticas 
escolares - discente e docente, continue esquecida ou em segundo plano? Se nos falta uma cultura de biblioteca, de leitura e de pesquisa na escola; se o livro é a fonte mais utilizada nos trabalhos escolares, conforme sinalizado por Moro e Estabel (2004); se as TIC invadem todo o social de maneira fascinante, atraente e imediata; e, se o número de escolas com internet já suplantou o das que têm biblioteca, logo medidas de incentivo à leitura e à pesquisa precisam ser pensadas e efetivadas.

A biblioteca é um lugar que reúne informações e conhecimento. Por conseguinte, tanto quanto a Web, ela precisa ser pensada como ferramenta fundamental para ensinar os alunos como se opera o acesso e como se faz uso das informações com relevância, significação e qualidade. Portanto, é preciso despertar o interesse e a curiosidade da sociedade para este local. Independentemente do suporte onde estão registradas; se em ambiente virtual ou na concretude de um livro impresso, por exemplo, as informações precisam ser compreendidas e re-significadas por aqueles que as utilizam. Tanto quanto os hardwares, os softwares, os sites e as bases de dados eletrônicas, as fontes impressas possuem uma "chave" de uso que precisa ser conhecida dos escolares. Essa "chave" é um facilitador de acesso à informação desejada ou precisada. Ela integra vários recursos. No livro, por exemplo, o sumário, o índice e o glossário, facilitam a vida de quem precisa operacionalizá-lo, mas é ainda pouco compreendido pela maioria dos escolares. Portanto, disponibilizar fontes informacionais, quer virtuais, impressas ou eletrônicas, tornou-se imprescindível, mas não mais do que saber lidar com elas. Hoje, mais do que ontem, é necessário pensar em orientar continuamente àqueles que precisam utilizá-las.

Para dar suporte a tal exercício é essencial se investir em biblioteca. Isto facilitará aos sujeitos escolares o acesso às fontes e a contínua capacitação para uma autonomia futura. Autonomia que, segundo Garcez e Souza (2008, p. 96), "Exige da escola uma biblioteca que efetivamente disponha de um corpo bibliotecário ativo e que promova uma adequada interação com os alunos e professores." Com a Lei 12.244/2010 (BRASIL, 2010a) a expectativa é de que em 2020 o Governo, com a participação de bibliotecários e educadores, tenha resolvido esta lacuna. 


\section{Escola e Pesquisa Escolar}

$\mathrm{O}$ acesso aos benefícios sociais advindos de um volume maior do saber socialmente construído é determinante para que os indivíduos tornem-se produtores e consumidores de serviços e de informações; para intervirem no social. Esta condição não está relacionada ao local onde os indivíduos estão situados - se em países com maior produção-geraçãoconstrução de conhecimento ou naqueles dependentes do bloco econômico mais forte. Em ambos os lados há potencial humano sendo desperdiçado. Investimento em educação e estímulo aos que estão em processo de aprendizagem e de ensino são fundamentais para uma participação e distribuição econômica mais igualitária, com repercussão local e global. No entanto, questiona-se: o que precisa ocorrer para a escola responder às necessidades atuais e futuras? Por certo, há várias possibilidades ou alternativas para resolver esse problema e acredita-se que uma delas seja a de orientar e acompanhar o aluno para e durante o processo da pesquisa escolar.

Segundo Campello (2010, p. 26) pesquisa escolar é:

um meio adequado para levar os alunos a trabalhar com autonomia em assuntos de seu interesse, a aprender a usar variadas fontes de informação e a mobilizar habilidades que poderão ser transferidas para outras situações de aprendizagem.

Para Moro e Estabel (2004, p. 2, grifo meu) a pesquisa escolar deve ser compreendida como "procedimento racional e sistemático, com método de pensamento reflexivo que requer um tratamento científico e tem como objetivo buscar respostas aos problemas sugeridos." Torna-se oportuno registrar que um dos possíveis pré-requisitos para que ocorra mudança de concepção de trabalho-cópia para pesquisa, será quando os envolvidos, escolares e nãoescolares, tiverem clareza da distinção entre pergunta e questão, resposta e reflexão. Pois, independentemente do meio de onde sairá a solução para a questão, ela exigirá do aluno/pesquisador, reflexão.

Bianchetti nos esclarece que:

Pergunta demanda respostas diretas a respeito do quando, como, onde e o quê [...] as questões, que implicam a necessidade de o(s) seu(s) autor(es) se posicionar(em) frente ao como e ao porquê, demandam reflexão $e$ a necessidade e capacidade de estabelecer relações e fazer novas sínteses. (BIANCHETTI, 2008, p. 57, grifo meu). 
Segundo Castoriadis (2010, p. 54), a educação deve instigar todos, jovens e nãojovens, à:

interrogarse constantemente para saber si actúan con conocimiento de causa y no movidos por una pasión o un prejuicio. No solamente los niños, porque la educación de un individuo, en sentido democrático, es una empresa que comienza con el nacimiento de ese individuo y que sólo se acaba con su muerte.

Para Bianchetti (2008) e Kruppa (1994), dentre outros, a escola tem feito com que o aluno continue manifestando e registrando respostas prontas, pontuais, decoradas. Com isso, ele vem perdendo a oportunidade de mostrar personalidade e pontos de vista nas manifestações, oral ou escrita, enquanto algo re-construído e não copiado. Para que o ensino e a aprendizagem fundamentem tal premissa, tornar-se-á necessário criar na escola ambiente com práticas sustentadas no desenvolvimento de competências para que o aluno saiba fazer uso da informação e prepare-se para uma autonomia profissional-pessoal-social futura. Sem lhe oferecer esse caminho como responsabilizá-lo pelo "aprendizado" copiado ou decorado?

A construção de um ambiente propício ao ensino da e com pesquisa requer da escola: a) formular e apresentar ao aluno uma boa questão, motivando-o para a pesquisa; b) indicar fontes seguras para iniciar o caminho; c) Ensinar a interpretar, mantendo-o distante do copiar/colar - do plágio; d) Orientar na sua produção escrita na tentativa de fazer surgir um texto que ele possa dizer-se autor; e, e) Estimular a socialização do resultado do trabalho aos demais colegas da classe e/ou da escola. Em síntese, estas são concepções baseadas na ótica do desenvolvimento de competências informacionais e da construção de conhecimento. (MOÇO, 2010).

Para Milanesi (1983, p. 52),

só uma nova concepção de escola poderia incorporar uma biblioteca escolar com os requisitos elementares de acesso a um acervo capaz de responder às questões básicas que os alunos possam formular, sendo ao mesmo tempo um estímulo ao levantamento de questões.

Se, a educação mediada pela troca e pela interação presencial entre os sujeitos escolares vêm revelando carências como as apresentadas pela OECD (2010) e pelo próprio Governo (BRASIL, 2010b), no que resultará a interação intensificada por fios, cabos e redes virtuais? A partir das considerações de Bernard Charlot (2005), como contornar tal situação, se a escola ainda não ultrapassou a condição de ambiente que transfere conhecimento?

Criticando a política neoliberal, Laval comenta que hoje, criou-se a idea de que: 
É o indivíduo 'responsabilizado', quer dizer, consciente das vantagens e dos custos do aprendizado que deve fazer as melhores escolhas de formação para seu próprio bem. Isso supõe que, para escolher de modo lúcido, o que ele deve aprender, ele seja bem informado pelas 'agências de orientação'. Elas liberarão sua motivação, lhe fornecerão informações pertinentes e lhe 'facilitarão a tomada de decisão.' (LAVAL, 2004, p. 53, grifo meu).

Mas como responsabilizar o indivíduo adulto por escolhas lúcidas se, quando criança, a escola exigiu dele mais respostas do que reflexão? Laval (2004) preocupa-se com a transformação da escola em algo que atenda unicamente aos interesses econômicos. Com isso, segundo esse autor, o Estado acabará se eximindo da garantia do bem estar social. Do contrário, o Estado daria todas as condições para que o indivíduo conseguisse alcançar a autonomia defendida pelo mundo econômico sem abandonar o ideal de cidadania.

Castoriadis (2010) alerta para que o indivíduo não seja privatizado. O autor considera que os meios de comunicação às vezes se ocupam em cativar o indivíduo para que pense menos, interfira menos e consuma mais.

Todo lo que acontece durante la vida del individuo continúa formándole y deformándole. La educaión esencial que la sociedad proporciona a su miembros, en las escuelas, los colegios, los institutos y las universidades es una educación instrumental, organizada esencialmente para aprender una ocupación profesional. Y, al lado de ésta, hay la outra educación, a saber las tonterías que difunde la televisión. (CASTORIADIS, 2010, p. 54 ).

No Memorando sobre a Educação e a formação ao Longo de Toda a Vida ${ }^{4}$, está, segundo Laval (2004), a diretriz da Comissão Européia para uma educação voltada exclusivamente para o emprego e a individualização. Para esse autor as TIC trouxeram uma nova concepção de sociedade - a de 'sociedade cognitiva'. Nela a aprendizagem é formada unicamente por:

'pontes', 'redes de aprendizado', 'rotas flexíveis', 'parcerias” e todas as formas de interpretação facilitadas pelo uso das novas tecnologias. [...] professores [...] se tornarão 'guias, tutores, e mediadores' que deverão acompanhar os indivíduos isolados no seu processo de formação. (LAVAL, 2004, p, 51-53).

\footnotetext{
${ }^{4}$ Ratificado pela Comissão Europeia, em Lisboa, em março de 2000. Cf. Peter Alheit e Bettina Dausien (2006), em 'Processo de formação e aprendizagens ao longo da vida', mostram que o conceito "aprendizagem ao longo da Vida", tem gerado muitas discussões pelas implicações econômicas e sociais. Abrangendo instituições e indivíduos, ele perpassa pelo quadro econômico e político (competitividade, a empregabilidade e a adaptabilidade das forças de trabalho) e pela liberdade do indivíduo (seu planejamento e engajamento social), aparecendo sob a dualidade 'instrumentalização' e 'emancipação'. Disponível em: $<$ http://www.scielo.br/scielo.php?script=sci_arttext\&pid=S1517-97022006000100011\&lng=pt\&nrm=iso>. Acesso em: 09 mar. 2012.
} 
Ainda, sobre a rede facilitada pelas TIC, Dupas (2001, p. 67) entende que as redes virtuais "vêm substituindo progressivamente as relações pessoais convencionais e criando uma socialização lúdica em substituição à socialização afetiva.” Campello (2010, p. 26) salienta que o processo da busca de informação pelos alunos é permeado por sentimentos de insegurança e de ansiedade, portanto é preciso "entender o lado afetivo do processo" quando, por exemplo, os alunos "não dominam o tema, estão preocupados com os prazos e com a nota, não sabem se vão encontrar informações suficientes. Precisam, portanto, de ajuda para aprender a lidar com esses sentimentos e avançar [...]." Afinal, como lidar com isso por meio de fios?

Sobre a questão da reciprocidade no mundo virtual, Santos (2006, p. 65), entende que “a globalização mata a noção de solidariedade, devolve o homem à condição primitiva do cada um por si e, como se voltássemos a ser animais da selva, reduz as noções de moralidade pública e particular a um quase nada."

Ainda, acerca do acesso à Web e à qualidade de uso desse canal, Bianchetti (2008, p. 58) alerta que "se tivermos presente que, estatisticamente, futebol e pornografia formam os dois sites mais visitados na internet, teremos a idéia mais exata da relação entre potencialidades e aproveitamento."

O Manifesto IFLA/UNESCO sobre a Internet (2002) ressalta o aspecto de se orientar os alunos para acesso a informação nesse ambiente. Nele há de tudo - de recursos valiosos aos incorretos, enganadores e ofensivos. Com isso fortalece o entendimento de que a biblioteca escolar é entendida como local onde os alunos podem ser orientados para usufruir com mais qualidade aquilo que o ambiente virtual oferece. (MANIFESTO, 2002).

Percebe-se, em Laval (2004) e em Santos (2006), preocupação de que a individualização culmine no controle daquilo que o indivíduo deverá/poderá ter acesso, aprender e construir. Isso poderá levá-lo a ser instrumento do capital; à simples condição de consumidor. A tendência é de que, com as estratégias econômico-capitalistas mediadas pelas TIC, os indivíduos tornem-se mais suscetíveis ao controle do que fazer e do que pensar. Certamente, tais questões perpassam por princípios de ordem moral e ética que, segundo Dupas, (2001, p. 74-75), são fundamentais para "o homem não destruir a si mesmo." Logo, o acesso à informação via TIC e uma futura qualidade do ensino favorecida por esse acesso, torna-se essencial orientar os alunos para que obtenham melhor aproveitamento com o uso dessa ferramenta. Afinal, lembra Bianchetti (2008, p. 58) que: 
Dispor de dados e informações é um pressuposto importante para o conhecimento, mas eles por si mesmos não são garantia suficiente para que os seus possuidores abandonem a atitude passiva de depositários. Conhecimento, nunca é demais repetir, tem a ver com construção.

O estudo sobre o sucesso e o fracasso escolar no Brasil, (IRELAND, 2007), realizado em parceria pelo Instituto Nacional de Pesquisas Educacionais Anísio Teixeira (INEP) e a Organização das Nações Unidas para a Educação, a Ciência e a Cultura (UNESCO), revelou que a biblioteca está, ainda, bastante distante de ser espaço onde se compartilham saberes, e

muito mais um espaço para o desenvolvimento de atividades artísticas ou lúdicas do que propriamente para leitura e pesquisa. Observa-se, assim, que os recursos oferecidos por uma biblioteca, por mais precária que esta seja, quase não são utilizados. Em síntese, as bibliotecas escolares pouco têm contribuído para a formação do leitor. (IRELAND, 2007, p. 270, grifo meu).

Faoro (2000) inquieta-se com a formação oferecida aos escolares e entende que há uma estreita relação entre essa formação à oferecida aos professores. Afirma ela que:

Nas escolas é comum ver professores pedindo para os alunos pesquisarem determinado assunto, mas o que eles fazem, em geral, é consultar em poucas ou apenas em uma obra as informações de que precisam. Esta atividade, embora possa contribuir para a ampliação das informações que o aluno possui não representa o verdadeiro sentido da pesquisa, nem mesmo a construção de conhecimentos, passando a ser apenas uma consulta. (FAORO, 2000, p. 79).

Garcez e Cunha (2011) argumentam que parte da ineficiência da educação está em a escola não contar com biblioteca e bibliotecário. Os problemas da leitura cuja origem está na Educação Básica, afetam vestibulandos e, por conseguinte graduandos e pós-graduandos. Essa situação, comum em nossas escolas, quando associada aos dados da OECD (2010) e do Censo Escolar (BRASIL, 2010b), por exemplo, nos sugere a necessidade de uma alteração curricular, contemplada, talvez, com uma gradual redução dos trabalhos escolares, e com o aumento, também gradual, de sua qualidade. Ao invés de cada professor trabalhar isoladamente, sobrecarregando os alunos com tantos afazeres, uma alternativa seria investir em pesquisa interdisciplinar, promovendo cooperação e troca de informação e de conhecimento entre professores-bibliotecário-alunos que, em rede, envolveria outros.

O problema da pesquisa sem reflexão ou trabalho-cópia ultrapassa fronteiras geográficas, envolve sujeitos escolares e não-escolares. Se isso traz prejuízo à maioria dos indivíduos por diminuir suas chances de progredir, por certo tem proporcionado mais poder a uma minoria que o detém. É no campo do poder que as dificuldades e as possibilidades de se 
alterar esse quadro se encontram. Conforme Moreira e Silva (1995) o poder está representado em todos os atos - dos emanados pelo Governo às ações dos sujeitos que estão presentes no cotidiano escolar, logo, pela interação, todos os indivíduos exercem poder e são influenciados por ele. Segundo Kruppa (1994, p. 30), as regras dão aos indivíduos sustentação à "função contínua de transmitir e criar conhecimentos." Portanto, se foram instituídas, também podem ser modificadas e/ou extintas.

\section{Considerações Finais}

Com as TIC, inegavelmente, o fluxo de informação tornou-se mais dinâmico passando a nos exigir maior agilidade nas decisões. Diante disso, os desafios enfrentados pela escola não tem sido poucos, nem pequenos. A debilitada convivência com biblioteca e os alunos tendo uma prática de pesquisa mais próxima da cópia, hoje acionada pelo $\mathrm{Crt} C \mathrm{Crtl} \mathrm{V}$, acabou contaminando todos os níveis de ensino.

O ideal de pesquisa escolar - com base na leitura, interpretação, reflexão, na escrita e na socialização do aprendizado oriundo desse processo -, será possível de ser viabilizado a partir de uma reforma curricular atrelada a investimentos e numa mudança de atitude daqueles que deverão estar envolvidos com ela, principalmente docentes e discentes. Nesse processo também estarão os demais educadores (orientadores educacionais, supervisores, bibliotecário e outros), condição imprescindível para que o bom uso da biblioteca e da informação no espaço escolar se dê de forma contínua e generalizada.

Entende-se que para haver melhoria na educação é necessário: a) privilegiar o acesso à informação e ensinar todos a lidar com ela desde a escola de Educação Básica; e b) existir na escola espaço e políticas que garantam esse acesso e esse ensino. Para amparar esse ideal é fundamental garantir a existência de diferentes laboratórios (de química, física, matemática, de informática, de leitura, de escrita, dentre outras possibilidades), e de biblioteca nas suas múltiplas faces (espaço para leitura, estudo, multimídia, hora do conto, orientação à pesquisa e outros), mas principalmente, a promoção do uso desses espaços para que o aluno, cativado, aprenda melhor e tenha condições de re-construir conhecimento a partir de ações implementadoras desse princípio.

Os estudos e a revisão da literatura apontam a necessidade de melhorar a educação. O entendimento é de que ela deve envolver os sujeitos escolares a ponto de saberem distinguir 
pergunta de questão, resposta de reflexão, na qual se educa para a autonomia. Há muitas carências a serem superadas para se chegar nesse ideal. Acredita-se que a Lei Federal $\mathrm{n}^{\circ}$ 12.244 de 2010 (BRASIL, 2010a), com um prazo de 10 anos para ser cumprida, contribuirá para minimizar esse quadro, mesmo concordando com Silva (2011), de que tal dispositivo precisa de urgente regulamentação. Sobre isto o que revelará o Censo Escolar 2011 ?

Na sociedade do século XXI talvez o desafio seja o de preparar a escola e o professor para que o aluno saiba buscar e interpretar informações. Nela o papel do professor não será mais o de transmissor de conhecimento, mas o de orientador. Certamente, escolas com biblioteca atenderão tal perspectiva. Também, escolas com bibliotecário terão condições de contribuir, ainda mais, para melhor qualificar o ensino e a aprendizagem, para que o desenvolvimento do espírito investigativo seja pensado e viabilizado a partir da escola.

\section{Referências}

BIANCHETTI, Lucídio. Da chave de fenda ao Laptop: tecnologia digital e novas qualificações: desafios à educação. 2. ed., rev. ampl. Florianópolis: EdUFSC, 2008.

BLATTMANN, Ursula; FRAGOSO, Graça Maria. Emoção em tecnologia da informação e da comunicação. In: Horizonte: Autêntica, 2003.

BRASIL. Lei $\mathrm{n}^{\circ} 12.244$ de 24 de maio de 2010. Dispõe sobre a universalização das bibliotecas nas instituições de ensino do País. Diário Oficial [da] República Federativa do Brasil, Brasília, DF, 25 maio 2010a. Disponível em: $<$ http://www.planalto.gov.br/ccivil_03/_Ato2007-2010/2010/Lei/L12244.htm>. Acesso em: 5 jan. 2011.

. Ministério da Educação. Instituto Nacional de Estudos e Pesquisas Educacionais Anísio Teixeira. Resumo técnico - Censo escolar 2010: versão preliminar. 2010b. Disponível em: $<\mathrm{http}: / /$ portal.mec.gov.br/index.php?option=com_content\&view=article\&id=16179>. Acesso em: 13 maio 2011.

CAMPELLO, Bernadete. O bibliotecário e a pesquisa escolar. Presença Pedagógica, Belo Horizonte, v. 16, n. 93, maio/jun., 2010, p. 24-29.

CASTORIADIS, Cornelius. El individuo privatizado. In: VIDAL, Dominique (Ed.). Utopías: antiguos y nuevos sueños. Santiago del Chile: Aún Creemos en los Sueños, 2010. p. 51- 57.

CENTRO DE ESTUDOS SOBRE AS TECNOLOGIAS DA INFORMAÇÃO E DA COMUNICAÇÃO (CETIC.Br). TIC domicílios e usuários 2010: total Brasil. set./nov. 2010. 
2010a. Disponível em: <http://www.cetic.br/usuarios/tic/2010-total-brasil/index.htm>. Acesso em: 15 mar. 2012.

TIC educação 2010: alunos. set./dez. 2010. 2010b. Disponível em:

<http://www.cetic.br/educacao/2010/alunos.htm>. Acesso em: 15 mar. 2012.

CHARLOT, Bernard. Da relação com o saber: elementos para uma teoria. Porto Alegre: Artmed, 2005.

DUPAS, Gilberto. Ética e poder na sociedade da informação: de como a autonomia das novas tecnologias abriga a rever o mito do progresso. 2.ed., rev. ampl. São Paulo: UNESP, 2001.

FAORO, Jucinara Carvalho. Um olhar sobre o mito do indissociável: a pesquisa no ensino e o ensino da pesquisa na graduação. 2000, 160 f. Dissertação (Mestrado em Educação), Centro de Ciência da Educação, UFSC, Florianópolis, 2000.

GARCEZ, Eliane Fioravante; CUNHA, Miriam Vieira da. O bibliotecário na escola de educação básica: depoimentos de profissionais de Santa Catarina. Informação \& Sociedade, João Pessoa, v. 21, n. 2, p. 121-131, maio/ago. 2011. Disponível em:

<http://www.ies.ufpb.br/ojs2/index.php/ies/article/view/9725/5985>. Acesso em: 17 nov. 2011.

; SOUZA, Francisco das Chagas de. A biblioteca no currículo da escola e a conduta do bibliotecário. In: ROMÃO, Lucília Maria Sousa (Org.). Sentidos da biblioteca escolar. São Carlos: Compacta, 2008. p. 93-108.

IRELAND, Vera. (Coord.). Repensando a escola: um estudo sobre os desafios de aprender, ler e escrever. Brasília: UNESCO: MEC/INEP, 2007. 331p. Disponível em:

<unesdoc.unesco.org/images/0015/001512/151253por.pdf>. Acesso em: 14 ago. 2010.

KRUPPA, Sonia M. Portella. Sociologia da educação. São Paulo: Cortez, 1994. (Coleção Magistério $2^{\circ}$ grau; Série Formação do Professor). Cap. 3, p. 81-112.

LAVAL, Christian. A escola não é uma empresa: o neo-liberalismo em ataque ao ensino público. Londrina: Planta, 2004.

LOBROT, Michel. Para que serve a escola? Lisboa: Terramar,1992.

MACIEL, Maria Lucia. Estímulos e desestímulos à divulgação do conhecimento científico. In: BAUMGARTEN, M. (Org.). Conhecimentos e redes: sociedade, política e inovação. Porto Alegre: Ed. UFRGS, 2005. p. 107-116.

MANIFESTO IFLA SOBRE A INTERNET. Tradução: Federação Brasileira de Associações de Bibliotecários, Cientistas da Informação e Instituições. 2002. Disponível em:

$<$ http://archive.ifla.org/III/misc/im-pt.htm>. Acesso em: 15 maio 2011.

MILANESI, Luiz. O que é biblioteca. São Paulo: Brasiliense, 1983. 
MOÇO, Anderson. As 5 etapas para realizar uma boa pesquisa escolar: passo a passo, os caminhos para seus alunos ganharem autonomia nos estudos. Nova escola, São Paulo, v. 25, n. 237, nov. 2010. Disponível em: <http://revistaescola.abril.com.br/planejamento-eavaliacao/planejamento/cinco-etapas-realizar-boa-pesquisa-escolar-607946.shtml>. Acesso em: 08 nov. 2010.

MOREIRA, Antonio Flávio; SILVA, Tomaz Tadeu. Sociologia e teoria crítica do currículo: uma introdução. In: Cortez, 1995. Cap. 1. p. 7-37. (Org.). Currículo, cultura e sociedade. 2. ed. São Paulo:

MORO, Eliane Lourdes da Silva; ESTABEL, Lizandra Brasil. A pesquisa escolar propiciando a integração dos atores-alunos, educadores e bibliotecários: irradiando o benefício coletivo e a cidadania em um ambiente de aprendizagem mediado por computador. Novas Tecnologias na Educação, Porto Alegre: UFRGS, v. 2, n. 1, p.1-10, mar. 2004. Disponível em: $<$ http://seer.ufrgs.br/renote/article/view/13662/7947>. Acesso em: 15 jan. 2012.

OECD. Programme for International Student Assessment. PISA 2009 scores and rankings by country/economy. 2010. Disponível em:

$<$ http://www.oecd.org/document/61/0,3746,en_32252351_32235731_46567613_1_1_1_1,00. html>. Acesso em: 14 maio 2011.

SANTOS, Milton. Por uma outra globalização: do pensamento único à consciência universal. 13. ed. Rio de janeiro: Record, 2006.

SILVA, Jonathas Luiz Carvalho. Perspectivas históricas da biblioteca escolar no Brasil e análise da lei 12.244/10. ACB: Bibliotecononomia em Santa Catarina. Florianópolis, v. 16, n. 2, p. 489-517, jul./dez., 2011. Disponível em:

$<$ http://revista.acbsc.org.br/index.php/racb/article/view/797/pdf_63>. Acesso em: 07 fev. 2011.

VERONESE, Juliana. Pesquisa TIC 2009. Revista .br, São Paulo, ano 2, ed. 3, 2010. p. 1823. Disponível em: <http://www.cgi.br/publicacoes/revista/edicao03/txt.htm>. Acesso em: 03 ago. 2011.

VOGT, Carlos. Informação e simulacro. ComCiência, Campinas, n. 18, mar. 2001. Disponível em: <http://www.comciencia.br/reportagens/socinfo/info03.htm>. Acesso em: 27 jul. 2011.

WAGNER, Flávio Rech. Habilidade e inclusão digital: o papel das escolas. 2010. Disponível em: <http://www.cgi.br/publicacoes/artigos/artigo64.htm>. Acesso em: 01 ago. 2011.

ZOUAIN, Deborah Moraes. Ciência e tecnologia: fatores de desenvolvimento. In:

Gestão de instituições de pesquisa. Rio de Janeiro: FGV, 2001. 